\title{
Plasma Etching for Failure Analysis of Integrated Circuit Packages
}

\author{
J. Tang ${ }^{\mathrm{a}, \mathrm{b}}$, J. B. J. Schelen ${ }^{\mathrm{c}}$, and C. I. M. Beenakker ${ }^{\mathrm{b}}$ \\ ${ }^{\text {a }}$ Materials Innovation Institute \\ ${ }^{\mathrm{b}}$ Delft Institute of Microsystems and Nanoelectronics (DIMES), \\ Laboratory of Electronic Components, Technology and Materials (ECTM) \\ ${ }^{\mathrm{c}}$ Electronic and Mechanical Support Division (DEMO) \\ Delft University of Technology, Delft, the Netherlands
}

\begin{abstract}
Plastic integrated circuit packages with copper wire bonds are decapsulated by a Microwave Induced Plasma system. Improvements on microwave coupling of the system are achieved by frequency tuning and antenna modification. Plasmas with a mixture of $\mathrm{O}_{2}$ and $\mathrm{CF}_{4}$ showed a high etching rate around 2 $\mathrm{mm}^{3} / \mathrm{min}$. The role of $\mathrm{O}_{2}$ and $\mathrm{CF}_{4}$ in etching molding compound is described. Plastic package with $38 \mathrm{um} \mathrm{Cu}$ bond wires and a $2 \mathrm{~mm}$ * $3.5 \mathrm{~mm}$ die inside is fully decapsulated in 20 minutes. Cu wires remain undamaged after decapsulation proving the efficiency of this method.
\end{abstract}

\section{Introduction}

Failure analysis on integrated circuit (IC) packages often requires decapsulation of the package. In plastic IC packages, molding compound is used for encapsulation. Epoxy (20 wt\%) and silica filler (60-80 wt\%) are the major components. Decapsulation is the step to open an IC package to facilitate the inspection and electrical examination of the die and wire bonds inside. The trend in IC packaging is to use copper as wire bond material due to its economical and performace advantages (1). However, in that case conventional hot nitric acid decapsulation cannot be used because nitric acid quickly reacts with copper and damages the copper wire bond.

Plasma etching is a potential technique for IC package decapsulation with inherent advantages of high selectivity and process control (2). However, with conventional plasma etching systems silica filler in the molding compound appears to be difficult to remove. Additional steps like blowing with high gas flow or chemical etching in HF are required to remove the silica residue. This leads to a painstakingly long time to fully decapsulate an IC package.

Microwave Induced Plasma (MIP) has shown its potential in decapsulation of plastic IC packages (3), (4). By adjusting the composition of the plasma gas the MIP system can easily remove the silica fillers in the molding compound thus the time needed to fully decapsulate a plastic IC package is about ten times shorter than conventional plasma etchers.

In previous experiments we improved the microwave coupling of the system by antenna modification. Power reflection is decreased from $50 \%$ to $15 \%$. In this paper, microwave coupling is further improved by using a frequency tuning method. Using these improved conditions the influence of $\mathrm{O}_{2}$ and $\mathrm{CF}_{4}$ on molding compound removal rate is investigated under less than $5 \%$ reflected power. 


\section{Experiment Setup}

The MIP system consists of a Sairem GMP-180W solid-state microwave generator ( $\mathrm{f}=2450+-20 \mathrm{MHz}, \mathrm{P}<180 \mathrm{~W}$ ), a lab made Beenakker type microwave resonant cavity (5), (6) and gas connections. Fig. 1 is a schematic of the MIP system. The cavity is designed to resonate in the $\mathrm{TM}_{010}$ mode. The electric field strength inside the cavity follows a zero order Bessel function and is at its maximum value in the center and zero near the periphery. The resonant frequency of the cavity is determined by the following equation: $D=2.405 c / \pi f$, where $\mathrm{D}$ is the inside diameter of the cavity, $f$ is the resonant frequency and c is the speed of light. For the cavity used in the experiments, D is $93 \mathrm{~mm}$ and this results in $f$ to be $2470 \mathrm{MHz}$. The cavity is intentionally designed to have a larger resonant frequency than $2450 \mathrm{MHz}$ in order to compensate for its decrease when a dielectric material is inserted.

Alumina discharge tubes with $6 \mathrm{~mm}$ outside diameter and $1.2 \mathrm{~mm}$ inside diameter are used. A K-type thermocouple is used to measure the plasma effluent temperature. Etching depth and diameter are measured with a Veeco Dektak 150 surface profiler.

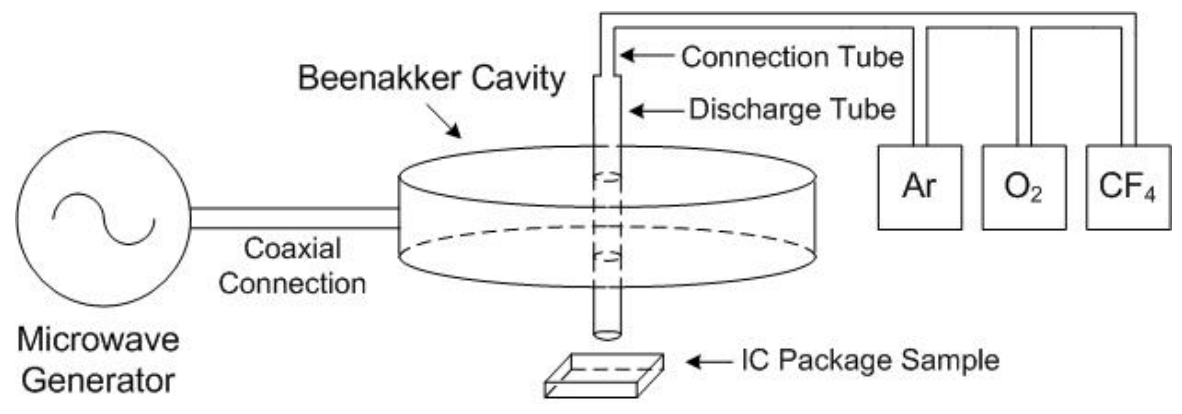

Figure 1. Schematic of the MIP system

\section{Improvements on the Microwave System}

Resonant cavities with a plasma inside behave differently from empty ones. The plasma inside can be regarded as a dielectric material with losses (7), (8). The equivalent permittivity of the plasma can be written as:

$$
\varepsilon_{p}=\varepsilon_{0}\left[1-\frac{n e^{2}}{m \varepsilon_{0} \omega(\omega+j v)}\right]
$$

where $n$ is the electron density in plasma, $\omega$ is the generator frequency, $v$ is the electron-neutral collision frequency, $\varepsilon_{0}$ is the permittivity of free space, $m$ is the effective mass of the electron, $e$ is the electron electric charge, $j$ is the imaginary operator. The real part of the permittivity explains the resonant frequency of the cavity to change. The imaginary part of the permittivity is related to the power absorption into the plasma. The plasma characteristic values $n$ and $v$ determine how the cavity performance changes once a plasma is ignited. In order for the MIP system to have a lowest reflected power, the system should be critically coupled when a plasma is present inside the cavity. This means the system should be designed to be decoupled when there is no plasma present.

In previous experiments we have shown that antenna modification inside the cavity greatly decreases power reflection from $50 \%$ to $15 \%$. To further decrease the reflected power, frequency tuning by using a variable frequency generator with a $40 \mathrm{MHz}$ tuning 
range is used. Changes in gas composition cause plasma characteristic to change and in turn influence the coupling. Fig.2 depicts the reflected power versus frequency of the generator and $\mathrm{CF}_{4}$ flow rate respectively. Input power is kept at $80 \mathrm{~W}$, Ar flow rate is 60 $\mathrm{L} / \mathrm{h}$ and $\mathrm{O}_{2}$ flow rate is $4 \mathrm{~L} / \mathrm{h}$. The reflected power is given as a percentage of the generator output power. The 3D surface shows the reflected power under different operating conditions. The $\mathrm{CF}_{4}$ flow is varied form 0 to $1.25 \mathrm{~L} / \mathrm{h}$ and the frequency from $2430 \mathrm{MHz}$ to $2470 \mathrm{MHz}$. As we can see from Fig.2 the coupling of the MIP system is sensitive to the frequency of the input microwave power. Frequency tuning with a 40 $\mathrm{MHz}$ range proved to be efficient and reduces reflected power from $15 \%$ to less than $5 \%$ in most cases.

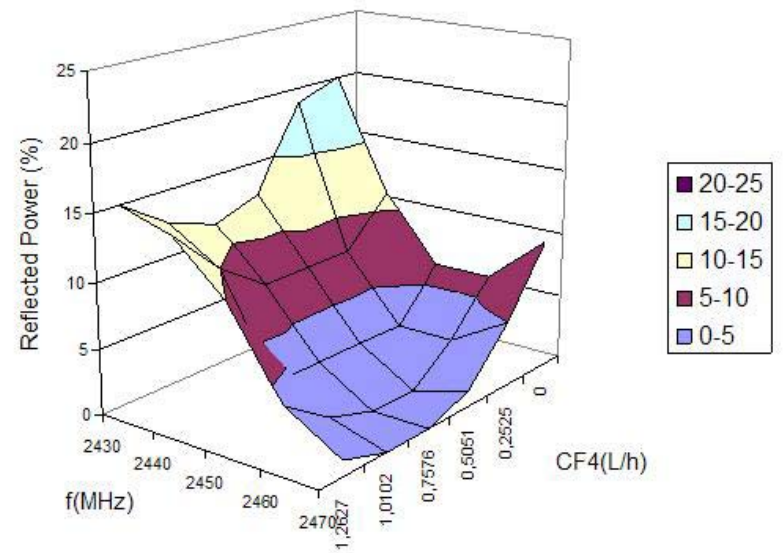

Figure 2. Reflected power versus frequency and $\mathrm{CF}_{4}$ flow

\section{Etching and Decapsulation Results}

Etching of molding compound with the improved MIP system is conducted with $\mathrm{Ar}+\mathrm{O}_{2}, \mathrm{Ar}+\mathrm{CF}_{4}$, and $\mathrm{Ar}+\mathrm{O}_{2}+\mathrm{CF}_{4}$ plasmas. In addition we performed decapsulation experiments with plastic packages containing $38 \mathrm{um} \mathrm{Cu}$ bonding wires. The reflected power during the experiments is kept below $5 \%$.

\section{$\underline{\text { Etching of molding compound using } \mathrm{Ar}+\mathrm{O}_{2}} \underline{\text { plasma }}$}

Oxygen gas added into the Ar plasma generates atomic oxygen that efficiently reacts with organic materials like photoresist and epoxy. As shown in Fig.3, molding compound exposed to $\mathrm{Ar}+\mathrm{O}_{2}$ plasma appears white after a few minutes. This is due to the fact that silica filler is left on the surface after epoxy is etched away. The filler residue does not appear as powder, it is agglomerated instead. Ultrasonic cleaning in water for 5 seconds proved to be efficient in removing the residue. However, the disadvantage of this procedure is that the wires under the residue are often damaged mechanically.

\section{Etching of molding compound using $\mathrm{Ar}+\mathrm{CF}_{4}$ plasma}

$\mathrm{CF}_{4}$ gas added into the Ar plasma generates atomic fluorine that reacts with silicon containing materials forming volatile $\mathrm{SiF}_{4}$. Thus silica filler can be removed by $\mathrm{Ar}+\mathrm{CF}_{4}$ plasma. Fig. 4 shows the top view on a partially decapsulated package. The etch duration at each position is 4 minutes. Assuming the etching profile to be a spherical cap, the etching rate is calculated to be around $0.15 \mathrm{~mm}^{3} / \mathrm{min}$ and is too low for practical applications. 


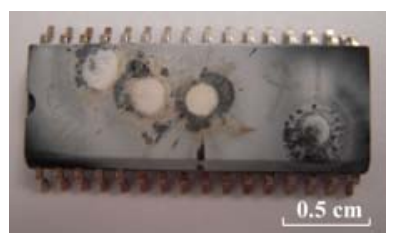

Figure 3. Profile after $\mathrm{Ar}+\mathrm{O}_{2}$ plasma etching

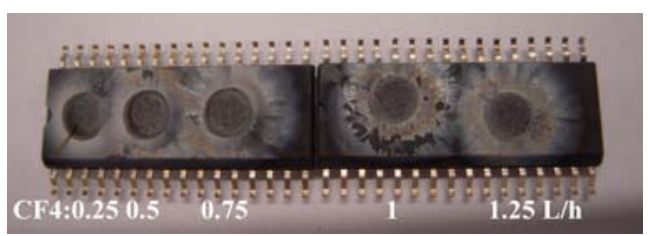

Figure 4. Profile after $\mathrm{Ar}^{+} \mathrm{CF}_{4}$ plasma etching with different $\mathrm{CF}_{4}$ flow

\section{Etching of molding compound using $\mathrm{Ar}^{+} \mathrm{O}_{2}+{ }_{\mathrm{CF}_{4}}$ plasma}

When both $\mathrm{O}_{2}$ and $\mathrm{CF}_{4}$ are added into the Ar plasma, the etching rate dramatically increases. With $80 \mathrm{~W}$ input power, $80 \mathrm{~L} / \mathrm{h} \mathrm{Ar}, 4 \mathrm{~L} / \mathrm{h} \mathrm{O}_{2}$, IC package samples are etched for 2 minutes under different $\mathrm{CF}_{4}$ additions. Fig.5 and Fig.6 show the etching profiles. As is shown in Fig.7, the increase of $\mathrm{CF}_{4}$ flow from $0 \mathrm{~L} / \mathrm{h}$ to $0.25 \mathrm{~L} / \mathrm{h}$ causes the etching rate to increase sharply from almost $0 \mathrm{~mm}^{3} / \mathrm{min}$ to $0.85 \mathrm{~mm}^{3} / \mathrm{min}$. In Fig.8, the addition of $\mathrm{CF}_{4}$ flow from $0.25 \mathrm{~L} / \mathrm{h}$ to $1.25 \mathrm{~L} / \mathrm{h}$ causes the etching rate to increase from 0.85 $\mathrm{mm}^{3} / \mathrm{min}$ to $2.45 \mathrm{~mm}^{3} / \mathrm{min}$.

The change of curve pattern between low and high $\mathrm{CF}_{4}$ addition can be explained in two ways. The first is when more $\mathrm{CF}_{4}$ is added, the dissociation of $\mathrm{CF}_{4}$ into atomic fluorine comes to a saturation thus the etching rate tends to saturate. The second is the atomic fluorine for the etching reaction with silica filler tends to saturate and causes the tangent of etching rate curve to decrease. The role of $\mathrm{CF}_{4}$ addition is to remove the silica agglomerate during etching. It is only needed that the surface of silica filler is etched by atomic fluorine so that the silica agglomerate structure becomes loose. Then it can be removed by the gas flow of the plasma effluent. White silica powder residue around the sample holder is observed during $\mathrm{Ar}+\mathrm{O}_{2}+\mathrm{CF}_{4}$ etching, this verifies the second explanation.

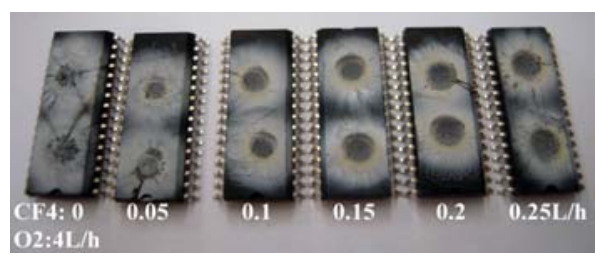

Figure 5. Profile after 2 minutes plasma etching with $\mathrm{CF}_{4} 0-0.25 \mathrm{~L} / \mathrm{h}$

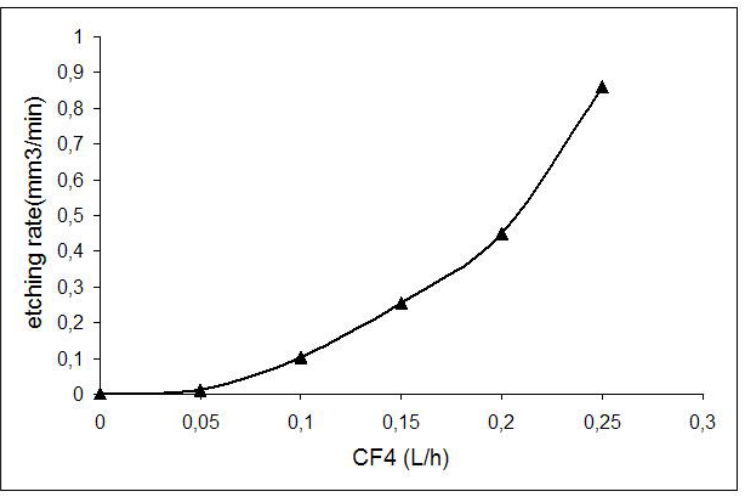

Figure 7. Etching rate versus $\mathrm{CF}_{4}$ flow rate $(0-0.25 \mathrm{~L} / \mathrm{h})$

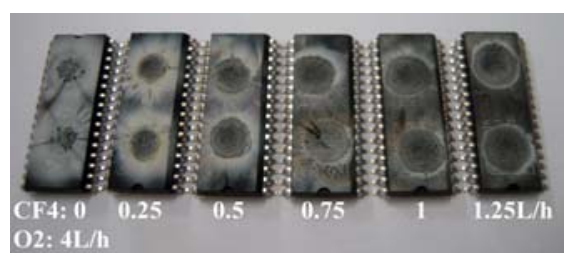

Figure 6. Profile after 2 minutes plasma etching with $\mathrm{CF}_{4} 0-1.25 \mathrm{~L} / \mathrm{h}$

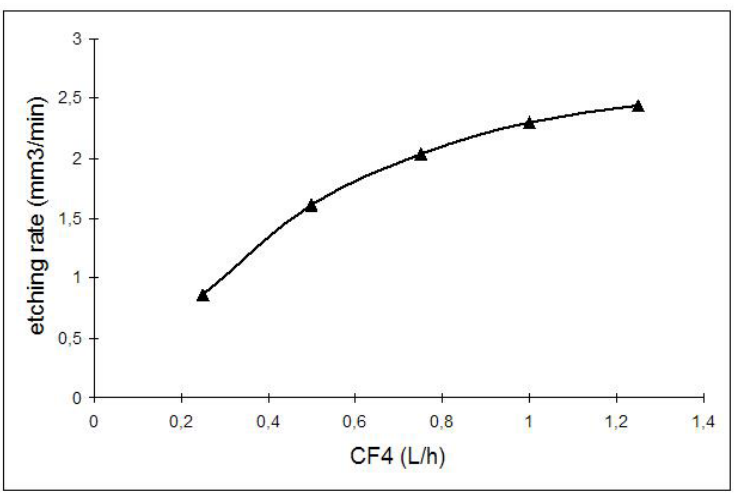

Figure 8. Etching rate versus $\mathrm{CF}_{4}$ flow rate $(0.25-1.25 \mathrm{~L} / \mathrm{h})$ 


\section{$\underline{\text { Decapsulation of plastic IC packages with } \mathrm{Ar}+\mathrm{O}_{2}} \underline{\mathrm{CF}}_{4} \underline{\text { plasma }}$}

Because of the different structures and materials used in a plastic IC package, it is advisable to perform decapsulation with the MIP system in steps. During the beginning of decapsulation, the top molding compound should be removed as fast as possible. The ratio of $\mathrm{O}_{2}$ and $\mathrm{CF}_{4}$ has to be optimized such that the rate of epoxy removal is the same with the rate of silica filler removal. When $\mathrm{Cu}$ bond wires and die are reached, recipes should be chosen that give a moderate etching rate, lower effluent temperature, and a higher etching selectivity to reduce possible damage.

In the next experiment a plastic IC package with $38 \mathrm{um} \mathrm{Cu}$ bond wires and a $2 \mathrm{~mm}$ * $3.5 \mathrm{~mm}$ die inside is decapsulated using $\mathrm{Ar}+\mathrm{O}_{2}+\mathrm{CF}_{4}$ plasma under an effluent temperature of around $400{ }^{\circ} \mathrm{C}$. The thickness of molding compound on top of the die is 1 $\mathrm{mm}$. Fig.9 depicts the package fully decapsulated using this method. The volume of molding compound being removed is $25 \mathrm{~mm}^{3}$ and the etching duration is 20 minutes. All the $\mathrm{Cu}$ bond wires and most part of the die appeared to be undamaged as inspected through an optical microscope. Fig.10 shows that the $38 \mathrm{um} \mathrm{Cu}$ bond wires are undamaged after MIP decapsulation as is indicated by the smooth surface and the reddish color of the wire. Fig.11 shows damaged copper wire after that we intentionally exposed the wire to extreme conditions of $100 \mathrm{~W}$ input power for 15 minutes. The surface of the wire becomes black and rough. Fig.12 shows the patterns on the die after decapsulation. In most places the die appears to be undamaged. However, as Fig.13 shows some damage cannot be excluded. This indicates over etching of the $\mathrm{Si}_{3} \mathrm{~N}_{4}$ passivation layer by the fluorine containing plasma. Improvements on recipe and process control are needed to reduce such kind of damage.

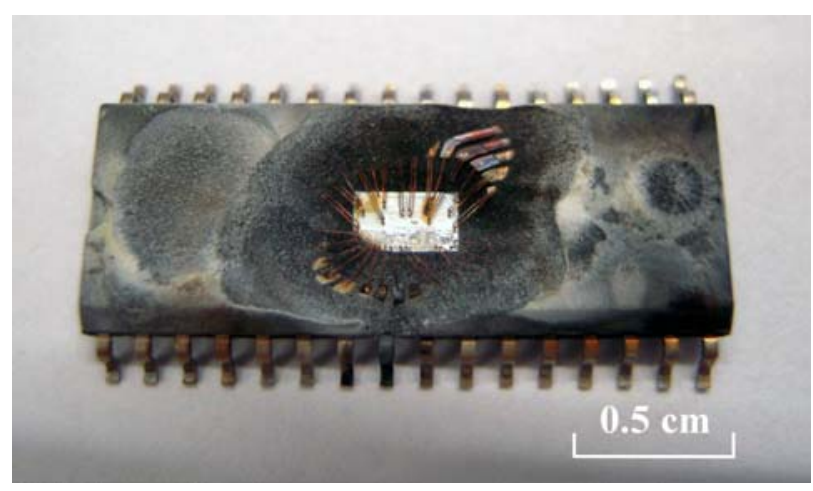

Figure 9. IC package decapsulated by MIP system

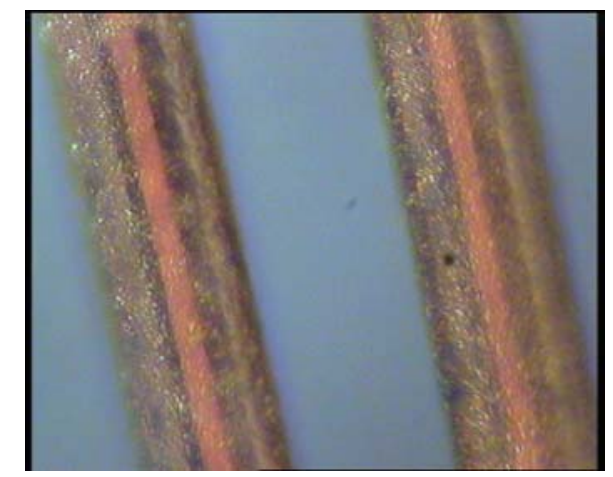

Figure 10. Undamaged Cu bond wires after decapsulation

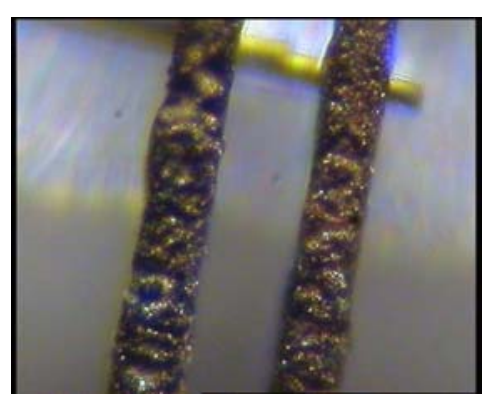

Figure 11. Intentionally damaged $\mathrm{Cu}$ wires

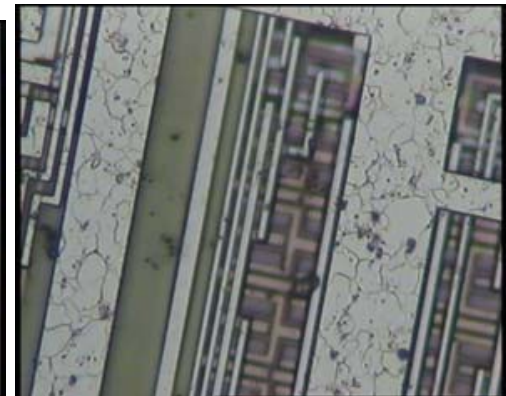

Figure 12. Undamaged patterns on the die

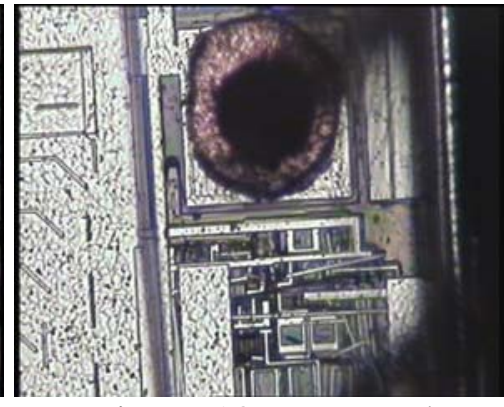

Figure 13. Damaged patterns on the die 


\section{Conclusions}

Microwave coupling of the MIP system is improved by a combination of antenna modification and frequency tuning. Reflected power is decreased from $50 \%$ to $5 \%$. With only $\mathrm{O}_{2}$ or $\mathrm{CF}_{4}$ plasma the etching rate of the molding compound is too slow for practical applications. The possible role of $\mathrm{O}_{2}$ and $\mathrm{CF}_{4}$ during etching is explained. With a proper mixture of $\mathrm{O}_{2}$ and $\mathrm{CF}_{4}$, the plasma showed sufficiently high etching rate and selectivity. Guidelines for using this MIP system for decapsulation of plastic IC packages are proposed. The high etching selectivity of the plasma ensures all the copper bond wires and most parts on the die to be undamaged after decapsulation.

\section{Acknowledgments}

This work is funded by the European Nanoelectronics Initiative Advisory Council (ENIAC) SE2A project. The authors wish to thank Prof. D. C. Schram, H. B. Profijt, Eindhoven University of Technology, for their helpful discussions in the areas of plasma physics. The authors would also like to thank H. Pomp at NXP Semiconductors and DIMES colleagues A. Akhnoukh, A. van den Bogaard, C. C. G. Visser, and R. P. van Viersen for their help on experiments.

\section{References}

1. N. Srikanth, S. Murali, Y.M. Wong, Charles J. Vath III, Thin Solid Films, Vol 462-463, pp. 339-345, (2004).

2. J. Thomas, J. Baer, P. Westby, K. Mattson, F. Haring, G. Strommen, J. Jacobson, S. S. Ahmad, A. Reinholz, 59 ${ }^{\text {th }}$ Electronic Components and Technology Conference, pp. 2011-2015, IEEE Conference Proceedings, (2009).

3. Q. Li, C. I. M. Beenakker, and J. Vath III, $7^{\text {th }}$ International Conference on Electronics Packaging Technology, IEEE Conference Proceedings, (2006).

4. J. Tang, J. B. J. Schelen, and C. I. M. Beenakker, $11^{\text {th }}$ International Conference on Electronics Packaging Technology \& High Density Packaging, pp. 1034-1038, IEEE Conference Proceedings, (2010).

5. C. I. M. Beenakker, Spectrochimica Acta, Vol. 31B, pp. 483-486, (1976).

6. C. I. M. Beenakker, Spectrochimica Acta, Vol. 33B, pp. 53-54, (1978).

7. J. L. Shohet and C. Moskowitz, J. Appl. Phys., Vol. 36, No. 5, pp. 1756-1759 (1965).

8. J. Hubert, M. Moisan and A. Ricard, Spectrochimica Acta, Vol. 34, pp. 1-10, (1979). 